sion, the network ties become less correlated as $H$ increases. In the limit of large $H$, the network becomes essentially a random graph (regardless of $\alpha$ ) and the search algorithm becomes a random walk. An effective decentralized search therefore requires a balance (albeit a highly forgiving one) of categorical flexibility and constraint.

Finally, by introducing parameter choices that are consistent with Milgram's experiment $\left(N=10^{8}, p=0.25\right)(1)$, as well as with subsequent empirical findings $(z=300, H=2)$ $(17,16)$, we can compare the distribution of chain lengths in our model with that of Travers and Milgram (1) for plausible values of $\alpha$ and $b$. As Fig. 3 shows, we obtain $\langle L\rangle \cong 6.7$ for $\alpha=$ 1 and $b=10$, indicating that our model captures the essence of the real small-world problem. This agreement is robust with respect to variations in the branching ratio, showing little change over the range $5<b<50$.

Although sociological in origin, our model is relevant to a broad class of decentralized search problems, such as peer-to-peer networking, in which centralized servers are excluded either by design or by necessity, and where broadcast-type searches (i.e., forwarding messages to all neighbors rather than just one) are ruled out because of congestion constraints (6). In essence, our model applies to any data structure in which data elements exhibit quantifiable characteristics analogous to our notion of identity, and similarity between two elementswhether people, music files, Web pages, or research reports - can be judged along more than one dimension. One of the principal difficulties with designing robust databases (18) is the absence of a unique classification scheme that all users of the database can apply consistently to place and locate files. Two musical songs, for example, can be similar because they belong to the same genre or because they were created in the same year. Our model transforms this difficulty into an asset, allowing all such classification schemes to exist simultaneously, and connecting data elements preferentially to similar elements in multiple dimensions. Efficient decentralized searches can then be conducted by means of simple, greedy algorithms providing only that the characteristics of the target element and the current element's immediate neighbors are known.

References and Notes

1. J. Travers, S. Milgram, Sociometry 32, 425 (1969).

2. D. J. Watts, S. J. Strogatz, Nature 393, 440 (1998).

3. S. H. Strogatz, Nature 410, 268 (2001).

4. J. Kleinberg, Nature 406, 845 (2000).

5. A.-L. Barabási, R. Albert, Science 286, 509 (1999).

6. L. Adamic, R. Lukose, A. Puniyani, B. Huberman, Phys. Rev. E 64, 046135 (2001).

7. B. J. Kim, C. N. Yoon, S. K. Han, H. Jeong, Phys. Rev. E 65, 027103 (2002).

8. H. C. White, Identity and Control (Princeton Univ. Press, Princeton, NJ, 1992).

9. G. Simmel, Am. J. Sociol. 8, 1 (1902).

10. F. S. Nadel, Theory of Social Structure (Free Press, Glencoe, IL, 1957).
11. R. Breiger, Social Forces 53, 181 (1974).

12. B. Bollobás, Random Graphs (Academic Press, New York, 1985).

13. M. Newman, D. Watts, Phys. Rev. E 60, 7332 (1999).

14. J. Kleinberg, Proc. 32nd ACM Symposium on Theory of Computing (Association for Computing Machinery, New York, 2000).

15. H. C. White, Social Forces 49, 259 (1970).

16. H. Bernard, P. Killworth, M. Evans, C. McCarty, G. Shelly, Ethnology 27, 155 (1988).
17. P. Killworth, H. Bernard, Soc. Networks 1, 159 (1978)

18. B. Manneville, The Biology of Business: Decoding the Natural Laws of the Enterprise (Jossey-Bass, San Francisco, 1999), chap. 5.

19. We thank J. Kleinberg for beneficial discussions. This work was funded in part by the National Science Foundation (grants SES-00-94162 and DMS0109086), the Intel Corporation, and the Columbia University Office of Strategic Initiatives.

23 January 2002; accepted 3 April 2002

\title{
Ascent of Dinosaurs Linked to an Iridium Anomaly at the Triassic-Jurassic Boundary
}

\author{
P. E. Olsen, ${ }^{1}$ D. V. Kent, ${ }^{1,2}$ H.-D. Sues, ${ }^{3}$ C. Koeberl, ${ }^{4}$ H. Huber, ${ }^{4}$ \\ A. Montanari, ${ }^{5}$ E. C. Rainforth, ${ }^{1}$ S. J. Fowell, ${ }^{6}$ M. J. Szajna, ${ }^{7}$ \\ B. W. Hartline ${ }^{7}$
}

Analysis of tetrapod footprints and skeletal material from more than 70 localities in eastern North America shows that large theropod dinosaurs appeared less than 10,000 years after the Triassic-Jurassic boundary and less than 30,000 years after the last Triassic taxa, synchronous with a terrestrial mass extinction. This extraordinary turnover is associated with an iridium anomaly (up to 285 parts per trillion, with an average maximum of 141 parts per trillion) and a fern spore spike, suggesting that a bolide impact was the cause. Eastern North American dinosaurian diversity reached a stable maximum less than 100,000 years after the boundary, marking the establishment of dinosaur-dominated communities that prevailed for the next 135 million years.

One of the most striking events in the Mesozoic was the rise to dominance of dinosaurs in terrestrial ecosystems. The cause and timing of their early Mesozoic ascent have been debated $(1-4)$, with difficulties in global correlation and low sampling density limiting the utility of global compilations and obscuring relations to possible forcing mechanisms. However, terrestrial vertebrate assemblages in eastern North America are temporally better constrained than elsewhere and provide high-resolution biological and geochemical data bearing on this issue. This region was within the tropics during the Triassic and contained rift valleys, which were formed during the incipient fragmentation of Pangea. These basins contain kilometer-thick sections of continental strata, termed the Newark Supergroup, which have recorded the rise of dinosaurs across $15^{\circ}$ of paleolatitude (5). Milankovitchtype climate cycles permeate the lacustrine strata of these basins, and in conjunction with paleomagnetic reversal stratigraphy, all of the

${ }^{1}$ Lamont-Doherty Earth Observatory of Columbia University, Palisades, NY 10964, USA. ²Department of Geological Sciences, Rutgers University, Piscataway, NJ 08854-8066, USA. ${ }^{3}$ Department of Palaeobiology, Royal Ontario Museum, 100 Queen's Park, Toronto, ON M5S 2C6, Canada. ${ }^{4}$ Institute of Geochemistry, University of Vienna, Althanstrasse 14, A-1090 Vienna, Austria. ${ }^{5}$ Osservatorio Geologio do Coldigiocom, 1-62020 Frontale di Aprio, Italy. 'Department of Geology and Geophysics, University of Alaska Fairbanks, Fairbanks, AK 99775-5780, USA. ${ }^{7}$ Reading Public Museum, 500 Museum Road, Reading, PA 19611, USA. fossils can be placed within a high-resolution astronomically tuned time scale $(6,7)$ (Fig. 1).

Here, we focus on material from 80 localities in four Newark Supergroup basins, consisting of reptile footprints $(8,9)$, skeletal remains $(2,10)$, and palynological material (11) keyed into the astronomically tuned time scale (Figs. 1 and 2). The footprints are abundant, well-preserved, and diverse, and they offer a temporal sampling of terrestrial vertebrate communities that is better than the sampling from skeletal material around the Triassic-Jurassic boundary $(4,8)$. On the basis of comparisons between the reconstructed osteology of footprints and known skeletal remains, the ichnogenus level generally corresponds to an osteological family or higher taxonomic level (Table 1). However, footprints sample the terrestrial communities directly, and major changes in footprint assemblage composition probably represent important ecological changes (12). Even with uncertainty in the nature of the trackmakers, well-preserved footprints offer a useful independent proxy of faunal change (13), and the observed stratigraphic changes in the ichnological assemblages are consistent with the changes seen in osteological remains (Fig. 1).

On the basis of compiled ranges tied to the time scale (Fig. 1), Newark Supergroup dinosaurian ichnotaxa show a slow increase in relative abundance and a stepped increase in maximum size below the Triassic-Jurassic boundary (9). The ornithischian dinosaurian ichnogenus Atreipus (14) is the most common dinosaurian 


\section{REPOR T S}

form until its last appearance in the middle Rhaetian. Atreipus, the occurrence of a rare form (unnamed dinosaurian genus 1), and the early Norian first appearance of "Anchisauripus" spp. produce a Norian peak in dinosaurian ichnotaxonomic diversity. Nondinosaurian ichnological diversity tends to increase throughout the Late Triassic, with no apparent taxonomic manifestation of the Carnian-Norian boundary. Above the Triassic-Jurassic boundary, non-dinosaurian footprint diversity drops, and dinosaurian ichnogeneric diversity increases to a maximum. At the same time, the maximum size of theropod dinosaur tracks increases by $\sim 20 \%$ with the first appearance of Eubrontes giganteus (15). This pattern is also consistent with that seen at lower temporal resolution at other Triassic-Jurassic sections globally (16).

Skeletal remains are much less common than footprints in eastern North America, but the record parallels the ichnological data. Specifically, the last appearance of procolophonids and phytosaurs and the first appearance of protosuchians occur in the youngest known Triassic osteological assemblage, dated at $\sim 800,000$ years $(\sim 800 \mathrm{ky})$ before the palynological Tri-
assic-Jurassic boundary (Fig. 1). The oldest Newark Supergroup Jurassic assemblages are from a variety of fluvial, aquatic, and eolian environments in Nova Scotia, dating to $<100$ ky after the boundary; Triassic forms, such as procolophonids and phytosaurs, are absent (2). This Jurassic osteological material is intimately associated with rich footprint assemblages containing Eubrontes giganteus but lacking Triassic-type footprints.

We found a modest Ir anomaly in the Newark rift basin at the palynologically identified Triassic-Jurassic boundary at the same sites producing much of the new Triassic vertebrate material (Fig. 2). The Ir anomaly of up to 285 parts per trillion (ppt), with an average maximum of $141 \mathrm{ppt}(0.285$ and $0.141 \mathrm{ng} / \mathrm{g})$, is seen at four correlative sections; the anomaly is stratigraphically coincident with a transient, but large, increase in fern spore abundance and is substantially above background levels of $\sim 50 \mathrm{ppt}(9,17$, 18). The increase in Ir and the spike in fern spore abundance occur in a white clay layer that is $\sim 1$ $\mathrm{m}(\sim 1 \mathrm{ky})$ above the last occurrence of Patinasporites densus and other typical Triassic pollen and spores and is $\sim 5 \mathrm{~m}(\sim 5 \mathrm{ky})$ below the first

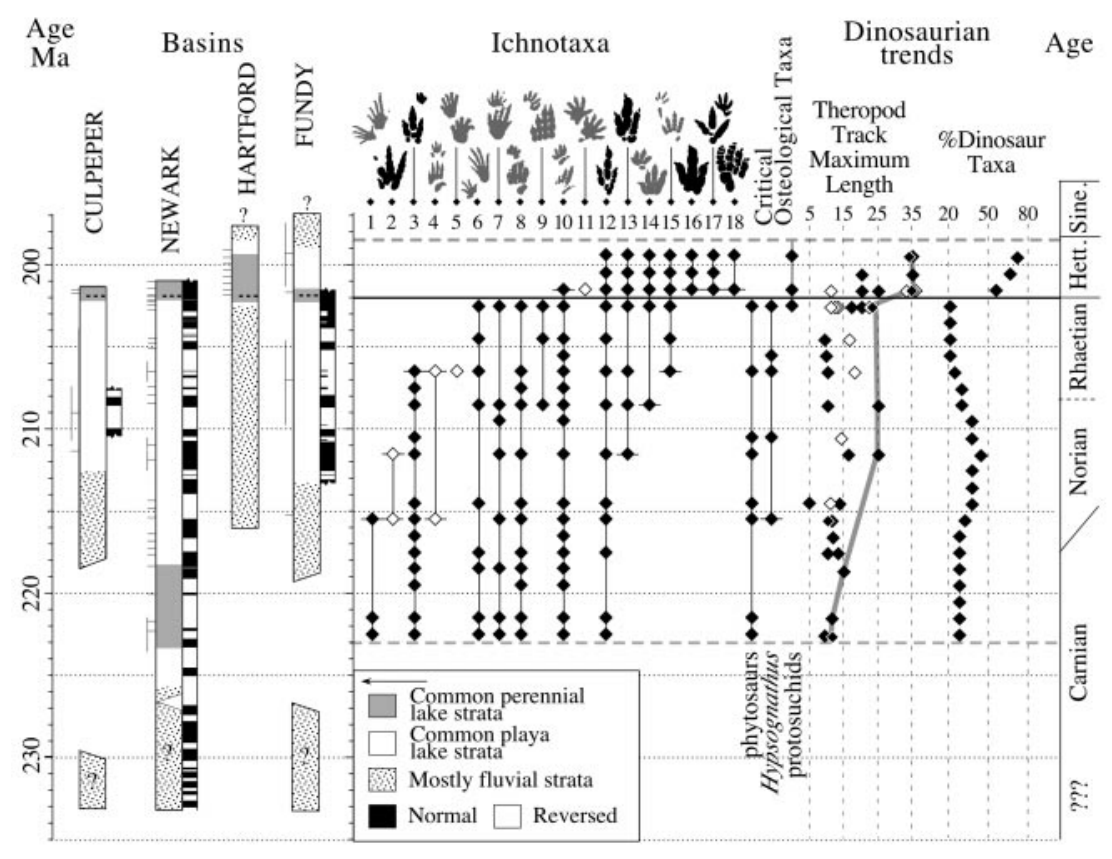

Fig. 1. Correlation of four key basins of the Newark Supergroup showing the temporal ranges of footprint ichnogenera and key osteological taxa binned into 1-My intervals showing the change in maximum theropod dinosaur footprint length (line drawn through maximum) and percent at each 1-My level of dinosaur taxa. Short, horizontal lines adjacent to stratigraphic sections show the position of assemblages, and the attached vertical lines indicate the uncertainty in stratigraphic position. Solid diamonds indicate samples of footprints, and open diamonds indicate samples with $<10$ footprints. Horizontal, dashed gray lines indicate the limits of sampling; thick gray line indicates trend in maximum size of theropod tracks; ?, age uncertain. Ichnotaxa are as follows: 1 , Rhynchosauroides hyperbates; 2 , unnamed dinosaurian genus 1; 3, Atreipus; 4, Chirotherium lulli; 5, Procolophonichnium; 6, Gwyneddichnium; 7, Apatopus; 8, Brachychirotherium parvum; 9, new taxon B (8); 10, Rhynchosauroides spp.; 11, Ameghinichnus; 12, "Grallator"; 13, "Anchisauripus"; 14, Batrachopus deweyii; 15, "Batrachopus" gracilis; 16, Eubrontes giganteus; 17, Anomoepus scambus; and 18, Otozoum moodii. Stratigraphic and magnetostratigraphic columns and correlations are modified from (5). Details of vertebrate assemblages are given in supplemental data (9). Correlation with the other rift basin sequences is based on the larger scale magnetic polarity pattern, Milankovitch cycle stratigraphy, palynology, and basalt geochemistry (20). Ma, million years ago; Hett., Hettangian; Sine., Sinemurian. typical Hettangian assemblage, consisting mostly of Corollina. Thus, within sampling resolution, the Ir anomaly and the "fern spike" are synchronous with the Triassic-Jurassic boundary. A few meters below the boundary is a thin zone of reversed magnetic polarity (chron E23r), identified at all three sections from which we have paleomagnetic analyses (7) (Fig. 2). Within $15 \mathrm{~m}$ above the boundary is the base of the oldest basalt flow in the Newark basin, the Orange Mountain Basalt, which is the oldest known North American part of the voluminous Central Atlantic Magmatic Province (CAMP) (19). On the basis of calibration by Milankovitch lake level cycles, the Triassic-Jurassic boundary occurs $\sim 20$ ky before the extrusion of the oldest basalt and $<20$ ky after chron E23r (20).

The westernmost of the four sections examined for an Ir anomaly allows a test of the possibility that the apparent Ir anomaly was caused by diagenetic migration of Ir at a strong redox boundary such as the carbonaceous horizon present at the other three sections (9). The westernmost boundary section consists of red and minor light gray clastic rocks, lacking black shales and coals, but does contain both the fern spike and thin zone of reversed magnetic polarity characteristic of the boundary interval. Despite the absence of a redox boundary, the Ir

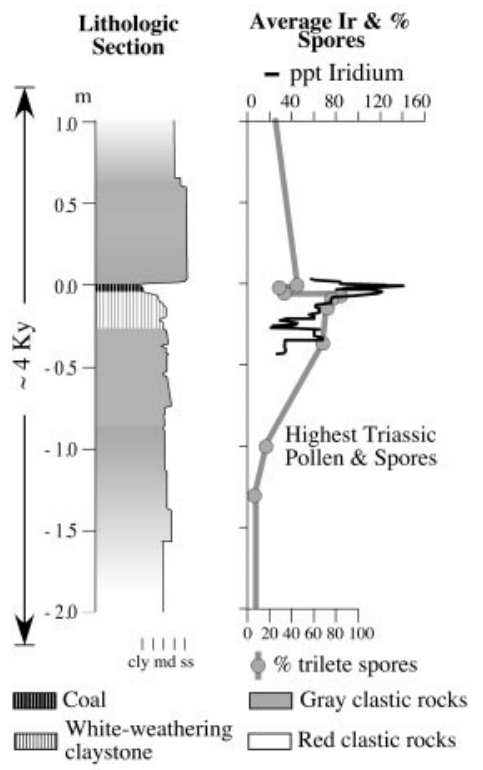

Fig. 2. Fine-scale correlation between the Ir anomaly and fern spike from the Jacksonwald syncline section of the Newark basin. The average Ir anomaly is based on four localities along strike within the Newark basin, each of which have an Ir anomaly in similar positions [details of data and averaging are included as supplemental material (9)]. The duration of the interval, as based on the linear extrapolation of accumulation rates, is derived from an astronomical calibration of the entire composite Jacsonwald syncline section (9). Percent spore data are averaged from three sections (11). Details of vertebrate assemblages and data averaging methods are given in the supplemental data (9). cly, claystone; md, mudstone; ss, sandstone. 


\section{R E P O R T S}

anomaly is associated with the fern spike (9). In addition, there are no correlations between Ir and $\mathrm{Al}_{2} \mathrm{O}_{3}$ or other major elements that may be subject to diagenetic enrichment (9), although additional sampling for Ir and other platinum group metals is needed to further test the meaning of the observed anomaly.

The lower resolution [1 million years (1 My)] terrestrial vertebrate pattern at the Triassic-Jurassic boundary, based on data from the Culpeper, Fundy, Hartford, and Newark basins (Fig. 1), is mirrored at higher resolution $(<20$ ky) in the Newark basin (9) around the Ir anomaly and fern spike. On the basis of the Milankovitch cyclostratigraphy, the last occurrence of Brachychirotherium parvum (a footprint form typical throughout the previous $20 \mathrm{My}$ of the eastern North American Triassic) is <20 ky older than the palynologically dated TriassicJurassic boundary, whereas the first occurrence of Eubrontes giganteus is $\sim 10 \mathrm{ky}$ younger. "Anchisauripus" and "Grallator" species occur with abundant Brachychirotherium parvum at a level that is $\sim 40$ ky older than the boundary. Thus, the transition from Triassic- to Jurassictype footprint assemblages occurred within a 50-ky interval that includes the boundary, fern spike, and Ir anomaly (9). These oldest examples of Eubrontes giganteus are as large as any in the rest of the Jurassic Newark Supergroup $(35 \mathrm{~cm})$.

These earliest known Jurassic track assemblages are of strikingly low diversity, despite identification of thousands of specimens. Only Rhynchosauroides sp., Batrachopus deweyii, "Grallator" spp., "Anchisauripus" spp., and Eubrontes giganteus are known from these beds. Herbivores (e.g., prosauropods and small ornithischians) appear within $100 \mathrm{ky}$ after the Triassic-Jurassic boundary, represented by both tracks and bones (2). Apart from an apparent increase in the frequency of prosauropod tracks (Otozoum) and the size of the largest ornithis-

Table 1. Correspondence between footprint and biological taxa. References and explanations are provided in the supplemental material (9).

\begin{tabular}{ll}
\hline \multicolumn{1}{c}{ Footprint taxon } & \multicolumn{1}{c}{ Biological counterpart (trackmaker) } \\
\hline Ameghinichnus & Advanced synapsid, possibly trithelodontid \\
Rhynchosauroides hyperbates & Lepidosauromorph or primitive archosauromorph \\
Rhynchosauroides spp. & Lepidosauromorphs \\
Chirotherium lulli & Crurotarsan, possibly aetosaurid \\
Procolophonichnium & Procolophonid parareptile \\
Gwyneddichnium & Tanystropheid \\
Apatopus & Phytosaur \\
Brachychirotherium parvum & Rauisuchian crurotarsan \\
New taxon B & Crurotarsan, possibly crocodylomorph \\
Batrachopus deweyii & Crocodylomorph \\
"Batrachopus" gracilis & Crocodylomorph \\
Unnamed dinosaurian genus 1 & Unknown dinosaur, perhaps herrerasaurid \\
Otozoum & Prosauropod dinosaur \\
"Grallator" & Small theropod dinosaur \\
"Anchisauripus" & Small- to medium-sized, theropod dinosaur \\
Eubrontes giganteus & Large theropod dinosaur \\
Atreipus spp. & Ornithischian dinosaur \\
Anomoepus scambus & Ornithischian dinosaur \\
\hline
\end{tabular}

chian tracks (Anomoepus), there is no obvious change in assemblage composition throughout the rest of the eastern North American record.

The association of an Ir anomaly, fern spike, and terrestrial mass extinction level is reministhe Cretaceous-Tertiary (K-T) boundary in western North America [e.g., (21)]. Shocked quartz, although not yet found in eastern North America $(2,22)$, has been reported at the marine Triassic-Jurassic boundary in Italy (23). Further similarities include a negative $\delta^{13} \mathrm{C}$ shift in both marine organic matter (24) and terrestrial plants (25) at the Triassic-Jurassic boundary, suggesting major perturbations in the carbon cycle. These similarities in pattern suggest a similarity in cause (2), namely, an impact of one or more large extraterrestrial bodies (26) and/or the environmental effects of the emplacement of giant igneous provinces (e.g., CAMP) (19). However, unlike the extinction at the K-T boundary, nonavian dinosaurs survived the Triassic-Jurassic boundary, and theropod dinosaurs rapidly increased in size.

Two scenarios might explain the increase in size in theropod dinosaurs across the Triassic-Jurassic boundary: First, the appearance of the much larger theropods represents a dispersal event from some unknown location, or second, it represents an evolutionary event. We favor the second hypothesis and suggest that the increase in size may be explained by a rapid (thousands of years) evolutionary response by the theropod survivors (which may have been quite small) to ecological release (27). This response would be similar to that inferred for reptiles on modern islands lacking competitors (28). The evolutionary hypothesis could be falsified by the discovery of large (Dilophosaurus-sized) theropod bones or diagnostic Eubrontes giganteus tracks in unquestionably Triassic strata. In any case, the evidence suggests that the dramatic decrease in nondinosaurian diversity was caused by an excent of the pattern produced by bolide impact at trinsic environmental catastrophe. The resulting drop in competitive pressure was the trigger for the global spread of large theropods, and these, along with the surviving prosauropods and ornithischians, established the familiar global dinosaurian-dominated ecological pattern seen across the terrestrial world for the succeeding $135 \mathrm{My}$.

\section{References and Notes}

1. A. J. Charig, Symp. Zool. Soc. London 52, 597 (1984).

2. P. E. Olsen, N. H. Shubin, M. E. Anders, Science 237, 1025 (1987).

3. M. J. Benton, in In the Shadow of the Dinosaurs: Triassic and Jurassic Tetrapod Faunas, N. C. Fraser, H.-D. Sues, Eds. (Cambridge Univ. Press, New York, 1994), pp. 366-397.

4. N. C. Fraser, H.-D. Sues, in In the Shadow of the Dinosaurs: Triassic and Jurassic Tetrapod Faunas, N. C. Fraser, H.-D. Sues, Eds. (Cambridge Univ. Press, New York, 1994), pp. 398-400.

5. P. E. Olsen, Annu. Rev. Earth Planet. Sci. 25, 337 (1997).

6. P. E. Olsen, D. V. Kent, Palaeogeogr. Palaeoclimatol. Palaeoecol. 122, 1 (1996).

7. D. V. Kent, P. E. Olsen, J. Geophys. Res. 104, 12831 (1999).

8. M. J. Szajna, B. W. Hartline, in The Great Rift Valleys of Pangea in Eastern North America: Volume 2, Sedimentology and Paleontology, P. M. LeTourneau, P. E. Olsen, Eds. (Columbia Univ. Press, New York, in press).

9. Additional information is provided in the supplemental material available on Science Online at www. sciencemag.org/cgi/content/full/296/5571/1305/ DC1.

10. H.-D. Sues, P. E. Olsen, D. M. Scott, P. S. Spencer, J. Vertebr. Paleontol. 20, 275 (2000).

11. S. J. Fowell et al., Geol. Soc. Am. Spec. Pap. 288, 197 (1994).

12. A. S. Cohen, J. Halfpenny, M. G. Lockley, E. Michel, Paleobiology 19, 433 (1993).

13. P. E. Olsen, P. M. Galton, Science 197, 983 (1977).

14. P. E. Olsen, D. Baird, in The Beginning of the Age of Dinosaurs, K. Padian, Ed. (Cambridge Univ. Press, New York, 1986), pp. 61-87.

15. The stepped increase in size of theropod dinosaur tracks at the Triassic-Jurassic boundary is more important than that in the early Norian because the latter occurs over the most poorly sampled interval (without an associated drop in nondinosaurian diversity), whereas the former occurs in the most densely sampled interval (Figs. 1 and 2) (9).

16. M. Lockley, A. P. Hunt, Dinosaur Tracks and Other Fossil Footprints of the Western United States (Columbia Univ. Press, New York, 1995).

17. The association of high fern spore levels in this clay was first described by R. L. Litwin [in (18)], who was also the first to describe the clay layer itself. Details of the analytical techniques and original data are given in the supplemental material (9).

18. R. C. Smith et al., Pa. Geol. 1988, 8 (1988).

19. A. Marzoli et al., Science 284, 616 (1999).

20. P. E. Olsen, R. W. Schlische, M. S. Fedosh, Mus. North. Ariz. Bull. 60, 11 (1996).

21. R. H. Tschudy, C. L. Pillmore, C. J. Orth, J. S. Gilmore, J. D. Knight, Science 225, 1090 (1984).

22. D. J. Mossman, R. G. Grantham, F. Laangenhorst, Can. J. Earth Sci. 35, 101 (1998).

23. D. M. Bice, C. R. Newton, S. McCauley. P. W. Reiners, C. A. McRoberts, Science 255, 443 (1992).

24. P. D. Ward et al., Science 292, 1148 (2001)

25. J. C. McElwain, D. J. Beerling, F. I. Woodward, Science 285, 1386 (1999).

26. J. G. Spray, S. P. Kelly, D. B. Rowley, Nature 392, 171 (1998).

27. E. O. Wilson, Am. Nat. 95, 169 (1961).

28. E. R. Pianka, Am. Nat. 146, 398 (1995).

29. P.E.O., D.V.K., and H.-D.S. were funded by grants from NSF (EAR-98-14475 and EAR-98-04851). Laboratory work was supported by Austrian Science Foundation grant Y58-GEO (to C.K.). This is a contribution to International Geological Correlation Programme 458 and is Lamont-Doherty Earth Observatory paper 6320.

20 August 2001; accepted 29 March 2002 